\title{
GOVERNANÇA CORPORATIVA E DESEMPENHO DAS AÇÕES DE EMPRESAS DO SETOR DE CONSUMO E VAREJO
}

\author{
CORPORATE GOVERNANCE AND PERFORMANCE OF \\ COMPANY STOCKS IN THE CONSUMER AND RETAIL SECTOR
}

\author{
GOBIERNO CORPORATIVO Y DESEMPEÑO DE LAS \\ ACCIONES DE EMPRESAS DEL SECTOR DE CONSUMO Y \\ MENUDEO
}

Guilherme André Peleglini Rocha

Especialista em Finanças Corporativas pela

Universidade Estadual de Londrina (UEL), Brasil /

Mestrando em Economia Aplicada pela Universidade de

São Paulo (USP), Brasil

guilhermerocha_7@hotmail.com

Eduardo Augusto do Rosário Contani

Doutor em Administração pela Universidade de São

Paulo (USP), Brasil / Professor do Mestrado

Profissional em Administração e da Graduação em

Administração da Fundação Escola de Comércio

Álvares Penteado (FECAP), Brasil / Antigo visiting

scholar na Universidade de Columbia, EUA (2011-

2012)

eduardocontani@gmail.com

Thais Lucimara da Silva Reco

Especialista em Finanças Corporativas pela

Universidade Estadual de Londrina (UEL), Brasil

tha_recco@hotmail.com
Contextus

ISSNe 2178-9258

Organização: Comitê Científico Interinstitucional Editor Científico: Carlos Adriano Santos Gomes Avaliação: double blind review pelo SEER/OJS

Recebido em 07/07/2017

Aceito em 20/12/2017 $2^{\mathrm{a}}$ versão aceita em 08/01/2017

\section{RESUMO}

O presente artigo analisa a correlação entre governança corporativa (GC) e desempenho das ações, orientado pelo propósito de aferir em que grau a classificação do nível de GC (N1, N2 e NM) e o comportamento de ações do setor de consumo e varejo listadas na B3 (Brasil, Bolsa, Balcão) podem ser mutuamente influenciados. Foi utilizada uma abordagem metodológica quantitativa, a partir das estatísticas obtidas pelos testes $\mathrm{t}$ e $\mathrm{F}$, para encontrar possíveis diferenças de risco e retorno entre o grupo com GC e o tradicional. Foram elencadas três hipóteses de pesquisa, comparando: (i) retorno de ações de empresas com GC e empresas listadas no segmento tradicional; (ii) retorno de ações de empresas com GC e Ibovespa; e (iii) risco de empresas com GC e empresas listadas no segmento tradicional. Verificou-se que as empresas listadas com GC não apresentaram retornos estatisticamente superiores às tradicionais, resultado encontrado em outros estudos (BAMPI et al., 2009; DOMINGOS; MOURA, 2015). Contudo, empresas com GC tiveram menor risco se comparadas às empresas listadas no segmento tradicional, confirmando uma das hipóteses de pesquisa e corroborando os achados de Matucheski, Clemente e Sandrini (2009) e Da Silva, Nardi e Junior (2012). Também não houve diferença estatisticamente significativa entre as empresas com GC e o Ibovespa, como observado em De Alencar et al. (2012).

Palavras-chave: Governança corporativa. Consumo. Varejo. B3. Ações.

\section{ABSTRACT}

This article analyses the correlation between corporate governance (CG) and stock performance, with the purpose of assessing the degree to which the classification of CG levels (N1, N2 and NM) and the behavior of stock exchange shares in the consumer and retail sector as listed in B3 (Brazil, Stock, Counter) can be mutually 
influenced. A quantitative methodological approach was used, drawn from the statistics obtained through $\mathrm{t}$ and $\mathrm{F}$ tests, to find possible differences with respect to risk and return between the group with $\mathrm{CG}$ and the traditional one. Three research hypotheses were raised in order to compare: (i) return of shares of companies with CG in contrast to that of companies listed in the traditional segment, (ii) return of shares of companies with CG and of those listed in Ibovespa and (iii) risk of companies with CG and of those listed in the traditional segment. It has been found that companies listed with CG do not present statistically superior returns to traditional companies, which is a result that was also found in other studies (BAMPI et al., 2009; DOMINGOS; MOURA, 2015). On the other hand, companies with CG have less risk when compared to the companies listed in the traditional segment, thus confirming one of the research hypoteses and corroborating the findings of Matucheski, Clemente and Sandrini (2009) and Da Silva, Nardi and Junior (2012). There has also been no statistically significant difference between the companies with CG and the Ibovespa, a result also found in De Alencar et al. (2012).

Key words: Corporate Governance. Consumption. Retail. B3. Stocks

\section{RESUMEN}

El presente artículo analiza la correlación entre gobierno corporativo (GC) y desempeño de las acciones, orientado por el propósito de medir en qué grado la clasificación del nivel de GC (N1, N2 y NM) y el comportamiento de las acciones del sector de consumo y menudeo enumeradas en la B3 (Brasil, Bolsa, Balcón) pueden ser mutuamente influenciados. Se utilizó un enfoque metodológico cuantitativo, a partir de las estadísticas obtenidas por las pruebas t y F, para encontrar posibles diferencias de riesgo y retorno entre el grupo con GC y el tradicional. Se presentaron tres hipótesis de investigación comparando (i) retorno de acciones de empresas con GC y listadas en el segmento tradicional, (ii) retorno de acciones de empresas con GC e listadas en el Ibovespa y (iii) riesgo de empresas con GC y listadas en el segmento tradicional. Se verificó que las empresas con GC no presentaron retornos estadísticamente superiores a las empresas tradicionales, resultado encontrado en otros estudios (BAMPI et al., 2009; DOMINGOS; MOURA, 2015). Sin embargo, las empresas con GC tuvieron menor riesgo si se las compara con las empresas enumeradas en el segmento tradicional, confirmando una de las hipótesis de investigación y corroborando los hallazgos de Matucheski, Clemente y Sandrini (2009) y Da Silva, Nardi y Junior (2012). También no hubo diferencia estadísticamente significativa entre las empresas con GC y el Ibovespa, como observado en De Alencar et al. (2012).

Palablas clave: Gobierno corporativo. Consumo. Menudeo. B3. Acciones

1 INTRODUÇÃO

$\mathrm{O}$ interesse pelo estudo da governança corporativa existe desde a década de 1940, período no qual pesquisas buscaram compreender a relação entre as regras de gestão e a maximização de capitais (MEANS, 1943). Nos últimos anos, o tema ganhou destaque por evidenciar mecanismos de alinhamento de interesses, mais conhecidos como soluções para os conflitos de agência, em meio a um ambiente afetado pelo desequilíbrio de informações (MARQUES, 2007; SAITO; SILVEIRA， 2008; DE ARRUDA; MADRUGA; DE FREITAS JUNIOR,
2009; $\quad$ MATIAS-PEREIRA， 2010; CORREIA; AMARAL; LOUVET, 2011; RIBEIRO et al., 2012; ROSSONI; MACHADO-DA-SILVA, 2013; SONZA; KLOECKNER, 2014; DE SANTANA et al., 2015; GOMES, 2016; EISSMANN; STEFENON; ARRUDA, 2017).

Para uma compreensão mais precisa acerca do conflito, caracterizam-se dois tipos de organizações: as clássicas e as modernas. Nas empresas denominadas clássicas, conforme Jensen e Meckling (1976), existe um único gestor, o qual é o principal acionista. Nesse contexto, a figura do proprietário e a do gestor se alinham em uma única pessoa, de modo 
que não há potencial de conflitos de interesse no processo decisório. No grupo das empresas ditas modernas, conforme relatam Machado e Rogers (2015), a propriedade e a gestão são segregadas, e esse fator pode fazer surgirem conflitos de interesse entre acionistas e gestores, ou até mesmo entre gestores de diferentes níveis.

É inegável, portanto, que a governança corporativa (GC) impacta nos âmbitos social, econômico e ambiental, e isso se dá com base na premissa de que, quanto maior for o grau de governança de uma empresa, maior será o alinhamento de interesses entre as partes envolvidas. Economias mais desenvolvidas, em geral, possuem um alto grau de governança (DO NASCIMENTO et al., 2013; DE SOUZA, 2016), e, de maneira oposta, países com baixa proteção aos acionistas minoritários e com menor grau de GC são penalizados com subprecificação de seus ativos, ceteris paribus (LA PORTA et al., 1999). Explica-se assim que a permanente busca por um melhor alinhamento de interesses ultrapassa 0 âmbito interno das organizações e se generaliza, chegando a atingir os agentes de mercado.

A análise de setores da economia permite verificar como as atividades podem afetar o desempenho de ações. Righi, Ceretta e Da Silveira (2012), ao estudarem seis índices setoriais, apontaram o de energia elétrica como o menos arriscado e com maiores índices nas relações de retorno e risco (índices de Sharpe, Sortino e Treynor). No entanto, o setor de consumo, medido pelo índice ICON (Índice BM\&F/Bovespa de Consumo), também teve destaque, com um dos menores betas (medida de risco). Os autores destacam que o ICON mede o comportamento das ações das empresas representativas dos setores de consumo cíclico e não cíclico.

No ano 2000, a Bolsa de Valores de São Paulo (BOVESPA), atualmente denominada por B3 (Brasil, Bolsa, Balcão), criou três níveis de GC, a fim de determinar regras específicas para as empresas que aderirem ao código de conduta. As organizações que aderem a tais níveis o fazem com a motivação de sinalizar ao mercado um comprometimento maior com os interesses dos acionistas. Pode-se relacionar esse fato com a ideia de que os agentes de mercado valorizam de forma positiva empresas com maior grau de transparência (ANDRADE et al., 2009).

Dessa forma, determinados pela B3, os níveis de governança seguem a ordem de complexidade das exigências como Nível 1 (N1), Nível 2 (N2) e Novo Mercado (NM). A criação desses níveis foi de extrema importância para o desenvolvimento e para o constante 
amadurecimento do mercado de capitais brasileiro. A recente expansão da GC requer um aporte de estudos empíricos que relacionem a adesão ao nível de governança com o retorno das ações. A questão de partida é, de maneira sintética: as empresas com melhor nível de governança tendem a possuir melhor desempenho de suas ações? Para responder a essa pergunta, três hipóteses de pesquisa foram elencadas comparando: (i) retorno de ações de empresas com GC e empresas listadas no segmento tradicional; (ii) retorno de ações de empresas com GC e Ibovespa; e (iii) risco de empresas com GC e empresas listadas no segmento tradicional.

O objetivo geral deste estudo é analisar as relações entre o desempenho das ações, nas dimensões retorno e risco, com a classificação do nível de GC, sendo eles N1, N2 e NM, nos quais as empresas brasileiras de capital aberto se enquadram. Os objetivos específicos são: a) identificar como se comportam o retorno e o risco de ações de empresas listadas na B3; b) comparar os resultados obtidos pela metodologia estatística de comparação de médias e variâncias frente a outros estudos; c) analisar as evidências de que a adesão aos níveis de GC, listados na B3, influenciam no retorno de suas ações.
$\mathrm{O}$ estudo se justifica pela importância de encontrar informações no ambiente brasileiro e transformá-las em conhecimentos sobre: como são resolvidos os desalinhamentos de interesses, como o resultado é transportado para a $\mathrm{GC}$ e que impactos são causados no comportamento das ações. Trata-se, na realidade, de um mapeamento a ser constantemente atualizado e, nesse sentido, a gerar dados com que futuras pesquisas poderão ocuparse. A análise dessa ambiência baseia-se no propósito de evidenciar se, realmente, a adesão aos níveis de GC, listados na B3, auxilia no desenvolvimento econômicofinanceiro das empresas, com impacto direto no retorno de suas ações. O recorte proposto, ao efetuar a análise do setor de consumo e varejo, visa dar destaque a uma parcela do PIB sensível às primeiras mudanças na condução econômica do país.

O artigo está organizado em quatro seções, sendo a primeira esta parte introdutória. A segunda apresenta a fundamentação teórica, e a terceira descrieve e ilustra os aspectos metodológicos. $\mathrm{Na}$ quarta, são apresentados e analisados os resultados para, na quinta seção, permitirem as principais inferências do estudo, sintetizadas na forma de considerações finais. 


\section{FUNDAMENTAÇÃO TEÓRICA}

Os tópicos abordados nesta seção abrangem: definições de GC, teoria de agência, níveis de GC no Brasil e pesquisas relacionando desempenho de ações e GC.

\subsection{Definições de GC}

Dentre os diversos autores que estudam e definem a GC, aqueles do relatório de Cadbury (1992) a consideram o sistema pelo qual as companhias são dirigidas e controladas, estando os conselheiros de administração situados no centro de qualquer discussão. Shleifer e Vishny (1997) acrescentam que essa prática deve ser entendida como um conjunto de mecanismos pelos quais os fornecedores de recursos das empresas garantem a obtenção do retorno sobre seu investimento. Por seu turno, La Porta et al. (2000) a definem como o conjunto de mecanismos que protegem os investidores externos da expropriação pelos internos (gestores e acionistas controladores). Lodi (2000), seguindo a mesma linha de raciocínio, define GC como o sistema de relacionamento entre acionistas, auditores independentes, executivos da empresa e conselho de administração.
No entendimento de Grün (2003), a governança é uma nova maneira de organizar o relacionamento entre empresa e mercado financeiro e está baseada na transparência contábil e no respeito a todos os acionistas. Rotta, Hillbrecht e Neto (2005) descrevem-na como o conjunto de práticas que alinham os interesses das diferentes partes de uma organização, com a finalidade de aumentar o valor da empresa e de viabilizar o acesso ao capital de terceiros.

Para Nascimento, Bianchi e Terra (2006), a definição se resume no esforço contínuo de alinhar objetivos da alta administração das empresas com interesses de acionistas ou proprietários, através de um monitoramento mais eficaz. Terra e Lima (2006) sustentam que a proteção aos acionistas minoritários é uma questão central para a GC, uma vez que o desenvolvimento do mercado de capitais e os financiamentos de novos projetos das empresas, em tese, deveriam ter, nos acionistas minoritários, uma alternativa acessível de captação de recursos. Segundo Konraht et al. (2016), a GC influencia os gestores a prestarem informações de melhor qualidade, ao abrirem mão do uso da discricionariedade para motivos particulares e divulgarem informações em congruência com os objetivos dos stakeholders da organização. 
De maneira geral e com base em todas as definiç̧ões citadas, os mecanismos criados de governança visam proteger os que têm menor força dentro das organizações, ou seja, os acionistas minoritários. O grau de maturidade do relacionamento que as organizações mantêm com seus diferentes agentes muda de acordo com o ambiente no qual estão inseridas. Shleifer e Vishny (1997) constataram que os distintos modelos de GC ao redor do mundo têm relação direta com o grau de evolução do sistema financeiro e legal. Os autores concluíram que, em países menos desenvolvidos, as práticas de governança são quase inexistentes.

Ainda segundo Shleifer e Vishny (1997), os grandes investidores representam seus próprios interesses, que não necessariamente coincidem com aqueles dos outros investidores da empresa ou com os dos gestores ou empregados. Da Silva, Kayo e Nardi (2016) relatam que, em empresas com propriedade dispersa, os gestores têm incentivos e poder para fazer investimentos ineficientes. A partir de tais fatos, é possível elucidar a teoria da representação ou de conflito de agência.

\subsection{Teoria de agência ou da representação}

A teoria de agência tem, como princípio norteador, a relação entre dois ou mais indivíduos. Jensen e Meckling (1976) consideram a relação de agência como um contrato pelo qual uma ou mais pessoas emprega outra para realizar algum serviço ou trabalho em seu favor, envolvendo a delegação de alguma autoridade de decisão para o agente. Segundo Hendriksen e Breda (1999, p. 139), um dos dois indivíduos é um agente do outro, chamado de principal. $O$ agente compromete-se a realizar certas tarefas para o principal, que em contrapartida compromete-se a remunerar o agente. A relação entre principal e agente não se restringe apenas àquela entre proprietários e administradores, sendo estendida em diversos outros campos, conforme se pode verificar no Quadro 1. 


\begin{tabular}{|c|c|}
\hline $\begin{array}{c}\text { Relação } \\
\text { principal - agente }\end{array}$ & O que o principal espera do agente? \\
\hline Acionistas - gerentes & $\begin{array}{l}\text { Os acionistas esperam que os gerentes maximizem a } \\
\text { sua riqueza (valor das ações). }\end{array}$ \\
\hline Debenturistas - gerentes & $\begin{array}{l}\text { Os debenturistas esperam que os gerentes } \\
\text { maximizem o seu retorno. }\end{array}$ \\
\hline Credores - gerentes & $\begin{array}{l}\text { Os credores esperam que os gerentes assegurem o } \\
\text { cumprimento de contratos de financiamento. }\end{array}$ \\
\hline Clientes - gerentes & $\begin{array}{l}\text { Os clientes esperam que os gerentes assegurem a } \\
\text { entrega de produtos, com maior qualidade, menor } \\
\text { tempo, maior serviço e menor custo. }\end{array}$ \\
\hline Governo - gerentes & $\begin{array}{l}\text { O governo espera que os gerentes assegurem o } \\
\text { cumprimento das obrigações fiscais, trabalhistas e } \\
\text { previdenciárias da empresa. }\end{array}$ \\
\hline Comunidade - gerentes & $\begin{array}{l}\text { A comunidade espera que os gerentes assegurem a } \\
\text { preservação dos interesses comunitários, cultura, } \\
\text { valores, meio ambiente etc. }\end{array}$ \\
\hline Acionistas - auditores externos & $\begin{array}{l}\text { Os acionistas esperam que os auditores externos } \\
\text { atestem a validade das demonstrações contábeis, } \\
\text { tendo como foco a rentabilidade e a eficiência. }\end{array}$ \\
\hline Credores - auditores externos & $\begin{array}{l}\text { Os credores esperam que os auditores externos } \\
\text { atestem a validade das demonstrações contábeis, } \\
\text { tendo como foco a liquidez e o endividamento. }\end{array}$ \\
\hline Gerentes - auditores internos & $\begin{array}{l}\text { Os gerentes esperam que os auditores internos } \\
\text { avaliem as operações sob a ótica de sua eficiência e } \\
\text { eficácia, gerando recomendações que agreguem } \\
\text { valor. }\end{array}$ \\
\hline Gerentes - empregados & $\begin{array}{l}\text { Os gerentes esperam que os empregados trabalhem } \\
\text { com o melhor de seus esforços, atendendo todas as } \\
\text { expectativas. }\end{array}$ \\
\hline Gerentes - fornecedores & $\begin{array}{l}\text { Os gerentes esperam que os fornecedores supram } \\
\text { todas as suas necessidades de materiais no momento } \\
\text { necessário e nas quantidades requisitadas. }\end{array}$ \\
\hline Dono de imóvel - corretor de imóvel & $\begin{array}{l}\text { O dono de um imóvel espera que o corretor busque a } \\
\text { melhor alternativa de compra. }\end{array}$ \\
\hline Investidor em fundo - administrador de fundo & $\begin{array}{l}\text { O investidor em um fundo espera que o } \\
\text { administrador gerencie seu investimento e obtenha o } \\
\text { melhor retorno. }\end{array}$ \\
\hline
\end{tabular}

Fonte: Dalmácio e Nossa (2004, p. 3).

A partir das relações expostas, Jensen e Meckling (1976) advertem que nenhum indivíduo pode desejar maximizar uma função que não seja a sua, pois o seu comportamento está fundamentado em suas preferências e seus objetivos. Os autores concluem dizendo que os executivos estão interessados no bem-estar pessoal e na redução de seus esforços, ao mesmo tempo em que os acionistas valorizam a maximização de seus investimentos, o que resulta no conflito de agência.

O conflito de agência se revela nas relações entre participantes de um sistema os quais, individualmente, possuem propriedade, controle e interesses distintos (MENDES, 2001). Weston e Brigham (2004) avaliam que, dentre todos os 
possíveis conflitos de agência, os principais se dão entre acionistas e administradores, bem como entre acionistas e credores. Para Saito e Silveira (2008), se ambas as partes agem tendo em vista a maximização das suas utilidades pessoais, existe uma boa razão para acreditar que o agente não agirá sempre no melhor interesse do principal.

Segundo Pereira e Souza (2017), a fim de reduzir os problemas de agência, as organizações implantam mecanismos de governança que buscam induzir, nos agentes, ações que assegurem os interesses entre as partes envolvidas. A composição do conselho de administração, a estrutura de propriedade, a remuneração dos dirigentes e a proteção dos minoritários são exemplos desses mecanismos (CORREIA et al., 2011). No Brasil, esses mecanismos foram classificados por ordem de complexidade e exigências - Nível 1 (N1), Nível 2 (N2) e Novo Mercado (NM), conforme classificação da B3. Além disso, alguns órgãos de referência de GC também foram criados, tais como o IBGC (Instituto Brasileiro de GC), a fim de contribuir para a elaboração de mecanismos de governança e o desempenho sustentável das organizações, bem como influenciar agentes da sociedade no sentido de maior transparência, justiça e responsabilidade.

\subsection{Níveis de GC no Brasil}

Garcia (2005) relata que as listagens da B3 se fizeram necessárias devido a uma crise pela qual passava o mercado de ações no Brasil no final da década de 1990. Criados em dezembro de 2000, os níveis de GC, conforme Colombo e Galli (2012), incluem regras para as empresas e as diferenciam conforme o grau de comprometimento com a governança, objetivando o desenvolvimento do mercado de capitais brasileiro.

Com essa classificação, busca-se dar maior transparência ao mercado como forma de atrair mais investidores e, em consequência, aumentar o volume de negociações da bolsa brasileira (AGUIAR; CORRAR; BATISTELLA，2004). Silva (2006) ressalta que as regras da B3 para listagem das companhias nos níveis diferenciados de GC tiveram, como propósito, fornecer um ambiente de negociação de ações que promovesse o interesse dos investidores e a valorização das companhias.

Colombo e Galli (2012) relatam que uma parte das companhias brasileiras já adotava práticas de GC antes do surgimento das regras para listagem da B3, porém não havia critérios adequados que pudessem sinalizar, aos investidores, quais as diferenças e vantagens oferecidas pelas 
empresas que adotavam tais práticas. De posse dessas informações, pode-se destacar que os níveis de GC criados pela B3 seguem um padrão de complexidade e exigências: o Nível 1 se caracteriza como o menor comprometimento com as regras de governança; o Nível 2, com um envolvimento intermediário; e o Novo Mercado adota $100 \%$ das regras.

Segundo a B3 (2017), as empresas listadas no Nível 1 devem adotar práticas que favoreçam a transparência e o acesso às informações pelos investidores. Para isso, divulgam informações adicionais às exigidas por lei, como por exemplo, um calendário anual de eventos corporativos. Quanto às empresas listadas no Nível 2, segundo a B3 (2017), têm o direito de manter ações preferenciais (PN). No caso de venda de controle da empresa, é assegurado, aos detentores de ações ordinárias e preferenciais, o mesmo tratamento concedido ao acionista controlador, prevendo-se, portanto, o direito de tag along de $100 \%$ do preço pago pelas ações ordinárias do acionista controlador.

Ainda segundo a B3 (2017), as ações preferenciais ao Nível 2 dão direito de voto aos acionistas em situações críticas, como a aprovação de fusões e incorporações da empresa e contratos entre acionista controlador e a empresa, sempre que essas decisões estiverem sujeitas à aprovação na assembleia de acionistas. Com relação ao Novo Mercado, a B3 (2017) ressalta que conduz as empresas ao mais elevado padrão de GC. Aquelas listadas nesse segmento podem emitir apenas ações com direito de voto, as chamadas ações ordinárias $(\mathrm{ON})$. No Quadro 2, são destacadas as principais diferenças e características entre os segmentos.

Quadro 2 - Comparativo dos segmentos de listagem

\begin{tabular}{|c|c|c|c|}
\hline $\begin{array}{c}\text { Características das } \\
\text { ações emitidas }\end{array}$ & NOVO MERCADO & NíVEL 2 & NíVEL 1 \\
somente de ações ON & $\begin{array}{c}\text { Permite a existência } \\
\text { de ações ON e PN } \\
\text { (com direitos } \\
\text { adicionais) }\end{array}$ & $\begin{array}{c}\text { Permite a existência } \\
\text { de ações ON e PN } \\
\text { (conforme legislação) }\end{array}$ \\
\hline $\begin{array}{c}\text { Percentual } \\
\text { mínimo de ações } \\
\text { em circulação } \text { (free } \\
\text { float) }\end{array}$ & $\begin{array}{c}\text { No mínimo 25\% de free } \\
\text { float }\end{array}$ & $\begin{array}{c}\text { No mínimo 25\% de } \\
\text { free float }\end{array}$ & $\begin{array}{c}\text { No mínimo 25\% de } \\
\text { free float }\end{array}$ \\
\hline $\begin{array}{c}\text { Distribuições } \\
\text { públicas de ações }\end{array}$ & $\begin{array}{c}\text { Esforços de dispersão } \\
\text { acionária }\end{array}$ & $\begin{array}{c}\text { Esforços de } \\
\text { dispersão acionária }\end{array}$ & $\begin{array}{c}\text { Esforços de dispersão } \\
\text { acionária }\end{array}$ \\
\hline $\begin{array}{c}\text { Vedação a } \\
\text { disposições } \\
\text { estatutárias }\end{array}$ & $\begin{array}{c}\text { Limitação de voto inferior } \\
\text { a 5\% do capital, quórum } \\
\text { qualificado e "cláusulas } \\
\text { pétreas" }\end{array}$ & $\begin{array}{c}\text { Limitação de voto } \\
\text { inferior a 5\% do } \\
\text { capital, quórum } \\
\text { qualificado e } \\
\text { "cláusulas pétreas" }\end{array}$ & $\begin{array}{c}\text { Não há regra } \\
\end{array}$ \\
\hline
\end{tabular}




\begin{tabular}{|c|c|c|c|}
\hline & NOVO MERCADO & NÍVEL 2 & NÍVEL 1 \\
\hline $\begin{array}{l}\text { Composição do } \\
\text { conselho de } \\
\text { administração }\end{array}$ & $\begin{array}{l}\text { Mínimo de } 5 \text { membros, } \\
\text { dos quais pelo menos } \\
20 \% \text { devem ser } \\
\text { independentes com } \\
\text { mandato unificado de até } \\
2 \text { anos }\end{array}$ & $\begin{array}{c}\text { Mínimo de } 5 \\
\text { membros, dos quais } \\
\text { pelo menos } 20 \% \\
\text { devem ser } \\
\text { independentes com } \\
\text { mandato unificado } \\
\text { de até } 2 \text { anos }\end{array}$ & $\begin{array}{c}\text { Mínimo de } 3 \\
\text { membros (conforme } \\
\text { legislação), com } \\
\text { mandato unificado de } \\
\text { até } 2 \text { anos }\end{array}$ \\
\hline $\begin{array}{c}\text { Vedação à } \\
\text { acumulação de } \\
\text { cargos }\end{array}$ & $\begin{array}{l}\text { Presidente do conselho e } \\
\text { diretor presidente ou } \\
\text { principal executivo pela } \\
\text { mesma pessoa (carência } \\
\text { de } 3 \text { anos a partir da } \\
\text { adesão) }\end{array}$ & $\begin{array}{l}\text { Presidente do } \\
\text { conselho e diretor } \\
\text { presidente ou } \\
\text { principal executivo } \\
\text { pela mesma pessoa } \\
\text { (carência de } 3 \text { anos } \\
\text { a partir da adesão) }\end{array}$ & $\begin{array}{c}\text { Presidente do } \\
\text { conselho e diretor } \\
\text { presidente ou } \\
\text { principal executivo } \\
\text { pela mesma pessoa } \\
\text { (carência de } 3 \text { anos a } \\
\text { partir da adesão) }\end{array}$ \\
\hline $\begin{array}{l}\text { Obrigação do } \\
\text { conselho de } \\
\text { administração }\end{array}$ & $\begin{array}{l}\text { Manifestação sobre } \\
\text { qualquer oferta pública de } \\
\text { aquisição de ações da } \\
\text { companhia }\end{array}$ & $\begin{array}{l}\text { Manifestação sobre } \\
\text { qualquer oferta } \\
\text { pública de aquisição } \\
\text { de ações da } \\
\text { companhia }\end{array}$ & Não há regra \\
\hline $\begin{array}{c}\text { Demonstrações } \\
\text { financeiras }\end{array}$ & Traduzidas para o inglês & $\begin{array}{c}\text { Traduzidas para o } \\
\text { inglês } \\
\end{array}$ & Conforme legislação \\
\hline $\begin{array}{c}\text { Reunião pública } \\
\text { anual }\end{array}$ & Obrigatória & Obrigatória & Obrigatória \\
\hline $\begin{array}{c}\text { Calendário de } \\
\text { eventos } \\
\text { corporativos } \\
\end{array}$ & Obrigatório & Obrigatório & Obrigatório \\
\hline $\begin{array}{l}\text { Divulgação } \\
\text { adicional de } \\
\text { informações }\end{array}$ & $\begin{array}{l}\text { Política de negociação de } \\
\text { valores mobiliários e } \\
\text { código de conduta }\end{array}$ & $\begin{array}{c}\text { Política de } \\
\text { negociação de } \\
\text { valores mobiliários } \\
\text { e código de conduta }\end{array}$ & $\begin{array}{c}\text { Política de negociação } \\
\text { de valores mobiliários } \\
\text { e código de conduta }\end{array}$ \\
\hline $\begin{array}{c}\text { Concessão de tag } \\
\text { along }\end{array}$ & $100 \%$ para ações ON & $\begin{array}{c}100 \% \text { para ações } \\
\text { ON e PN }\end{array}$ & $\begin{array}{l}80 \% \text { para ações ON } \\
\text { (conforme legislação) }\end{array}$ \\
\hline $\begin{array}{l}\text { Oferta pública de } \\
\text { aquisição de ações } \\
\text { no mínimo pelo } \\
\text { valor econômico }\end{array}$ & $\begin{array}{l}\text { Obrigatoriedade em caso } \\
\text { de cancelamento de } \\
\text { registro ou saída do } \\
\text { segmento }\end{array}$ & $\begin{array}{l}\text { Obrigatoriedade em } \\
\text { caso de } \\
\text { cancelamento de } \\
\text { registro ou saída do } \\
\text { segmento } \\
\end{array}$ & Conforme legislação \\
\hline $\begin{array}{c}\text { Adesão à câmara } \\
\text { de arbitragem do } \\
\text { mercado }\end{array}$ & Obrigatório & Obrigatório & Facultativo \\
\hline
\end{tabular}

Fonte: Adaptado de B3 (2017).

Vários estudos buscaram analisar a correlação entre desempenho e GC, tanto no Brasil como no exterior. Essa relação não possui uma opinião homogênea entre os pesquisadores, conforme pode ser observado em alguns estudos nacionais e internacionais.

\subsection{Pesquisas relacionando desempenho de ações e GC}

\section{Dos Santos e Pedreira (2008)} tiveram como objetivo apresentar os resultados de uma pesquisa estatística que analisa o comportamento dos preços das ações de empresas do setor de papel e celulose, após a adesão ao Nível 1 de GC. Constataram que, para todas as empresas 
pesquisadas, o valor de suas ações sofreu significativa valorização após a data de migração para o Nível 1.

Matucheski, Clemente e Sandrini (2009) visaram compreender a relação entre GC e a volatilidade das ações negociadas na B3 na crise financeira de 2008. O resultado dessa pesquisa, segundo eles, sugere que a GC consegue reduzir a volatilidade das ações em períodos de incerteza, principalmente quando considerado o risco de mercado.

As ações classificadas no Novo Mercado não apresentam rendimento superior às demais (Bampi et al., 2009). Contudo, se comparado o IGC (Índice de GC) ao Ibovespa, há diferença de retorno (Serra et al., 2009).

Meurer (2010) verificou se a adesão e consequente negociação das ações nos níveis especiais de GC reflete-se em um retorno diferenciado das ações no mercado de capitais. Com esse estudo, o autor concluiu que existem diferenças de desempenho entre os níveis de governança do mercado de capitais brasileiro; isso, contudo, não é garantia de uma rentabilidade positiva em relação ao mercado tradicional.

A iniciativa das empresas em aderir aos níveis de governança impacta risco e retorno dos preços de fechamento de suas ações (DA SILVA; NARDI; JUNIOR, 2012). Os resultados obtidos mostraram que as médias dos retornos das ações empresariais não apresentaram diferenças significativas antes e após a data de adesão aos níveis de GC. Mas as proxies de risco apresentaram-se significativamente diferentes.

De Alencar et al. (2012) realizaram um estudo comparando as ações cotadas no IGC (Índice de GC) em relação às ações cotadas no Índice Bovespa no que se refere à distribuição de dividendos. Concluíram que as práticas de GC não implicam, necessariamente, melhor distribuição de dividendos para os acionistas.

A adesão ao nível mais exigente de GC (Novo Mercado) constitui-se como passo fundamental para a capacidade de geração de valor aos acionistas (GAMA et al., 2013). A boa governança contempla justa estrutura legal, boa comunicação externa e interna, busca consenso nas relações sociais, desenvolvimento econômico e permanentes fiscalizações. Contudo, ao contrário do estudo de Gama et al. (2013), Nassiff (2014) evidenciou resultados sem tendência de criação ou destruição de valor das empresas que aderem a boas práticas.

As diferenças de resultados econômico-financeiros entre duas 
empresas no setor de varejo foram apontadas por Costa (2015), levando à hipótese de que existem outras variáveis, além daquelas registradas pela contabilidade, que contribuem para a avaliação de uma empresa e a atração de investidores.

De Oliveira Lima et al. (2015) analisaram a relação entre os diferentes níveis de GC das empresas e o aumento do seu valor de mercado, ou seja, examinaram se, para níveis mais elevados de governança, há melhor desempenho econômico. Nesse estudo, foram obtidas evidências de que as empresas listadas nos níveis mais elevados do mercado diferenciado possuem melhor desempenho econômico, medido em termos de variação média do valor de mercado.

Domingos e Moura (2015) investigaram a associação entre a reputação corporativa e o desempenho das maiores companhias abertas do Brasil. Com base nos resultados do teste aplicado, nenhuma evidência pode ser inferida sobre a associação entre reputação corporativa e desempenho.

$$
\text { McConnell e Qianru (2016) }
$$
exploraram mudanças regulatórias e mostraram que uma melhor GC instiga as empresas a divulgar os planos de sucessão, o que causa uma redução significativa na volatilidade do retorno das ações, o fortalecimento dos $C E O s$ em exercício e as chances de contratar sucessores menos qualificados.

Wang e Joseph (2017) investigaram se a governança interfere na performance financeira das organizações. Os resultados sugerem que, se as empresas implementam a governança CSR (corporate social responsibility) com sucesso para gerar bons resultados, ela exerce um papel importante no desempenho financeiro das mesmas.

Verificou-se, portanto, que parte dos estudos (BAMPI et al., 2009; MEURER, 2010; SILVA; NARDI; JUNIOR， 2011; NASSIFF， 2014; DOMINGOS; MOURA, 2015) não encontra relação entre GC e desempenho de ações ou valor da empresa. Por sua vez, essa correlação é positiva entre GC e geração de valor (MATUCHESKI; CLEMENTE; $\quad$ SANDRINI, 2009; SANTOS; PEDREIRA, 2009; DE ALENCAR et al., 2012; GAMA et al., 2013; DE OLIVEIRA et al., 2015; MCCONNELL; QIANRU, 2016; WANG; JOSEPH, 2017).

\section{METODOLOGIA}

A presente pesquisa é caracterizada como exploratória e quantitativa. A população é constituída por 40 empresas 
listadas na B3, que atuam no setor de consumo e varejo. A escolha do setor se justifica como tentativa de mensurar empresas que, em tese, poderiam ser homogêneas entre si, no que tange ao comportamento de seus resultados financeiros.

Os dados foram coletados do site da B3, referentes aos dias 28/12/2014 a
31/12/2016, ou seja, o período de tempo em que o país teve as menores taxas de crescimento do PIB nos últimos 10 anos.

As cotações diárias coletadas foram traduzidas em dados semanais, obtendo um total de 105 observações. As empresas são classificadas em algum nível de GC (N1, N2 ou NM), ou estão listadas no segmento tradicional (T), conforme o Quadro 3.

Quadro 3 - Empresas que compõem a amostra

\begin{tabular}{|c|c|c|c|c|c|}
\hline Empresa & Cód. Negociação & Segmento & Empresa & Cód. Negociação & Segmento \\
\hline ALPARGATAS S.A & ALPA3.SA & $\mathrm{N} 1$ & Lojas Americanas & LAME4.SA & $\mathrm{T}$ \\
\hline Advanced-DH & ADHM3.SA & $\mathrm{T}$ & Lojas Renner & LREN3.SA & $\mathrm{NM}$ \\
\hline Amazon & AMZO34.SA & $\mathrm{T}$ & Magazine Luiza & MGLU3.SA & NM \\
\hline Ambev & ABEV3.SA & $\mathrm{T}$ & Marfrig & MRFG3.SA & NM \\
\hline Arezzo & AZZ3.SA & NM & Lojas Marisa & AMAR3.SA & NM \\
\hline B2W Digital & BTOW3.SA & $\mathrm{NM}$ & M Dias Branco & MDIA3.SA & NM \\
\hline Bahema & BAHI3.SA & $\mathrm{T}$ & Minerva & BEEF3.SA & NM \\
\hline BRF S.A & BRFS3.SA & $\mathrm{NM}$ & Natura & NATU3.SA & NM \\
\hline Hering & HGTX3.SA & NM & Pão de Açúcar & PCAR4.SA & $\mathrm{N} 1$ \\
\hline Coteminas & CTNM4.SA & $\mathrm{T}$ & Pettenati & PTNT4.SA & $\mathrm{T}$ \\
\hline Dufry & DAGB33.SA & $\mathrm{T}$ & Restoque & LLIS3.SA & $\mathrm{NM}$ \\
\hline Excelsior & BAUH4.SA & $\mathrm{T}$ & Santanense & CTSA3.SA & $\mathrm{T}$ \\
\hline Graziotin & CGRA3.SA & $\mathrm{T}$ & São Martinho & SMTO3.SA & $\mathrm{NM}$ \\
\hline Grendene & GRND3.SA & NM & Saraiva & SLED4.SA & $\mathrm{N} 2$ \\
\hline Guararapes & GUAR3.SA & $\mathrm{T}$ & Ser Educa & SEER3.SA & NM \\
\hline Hypermarcas & HYPE3.Sa & NM & Springs Global & SGPS3.SA & NM \\
\hline IMC Holdings & MEAL3.SA & NM & T4F Entret. & SHOW3.SA & $\mathrm{NM}$ \\
\hline JB Duarte & JBDU4.SA & $\mathrm{T}$ & Teka & TEKA4.SA & $\mathrm{T}$ \\
\hline JBS Friboi & JBSS3.SA & NM & Renaux & TXRX4.SA & $\mathrm{T}$ \\
\hline Karsten & CTKA4.SA & $\mathrm{T}$ & Vulcabras & VULC3.SA & $\mathrm{T}$ \\
\hline
\end{tabular}

Fonte: os autores.

Para a análise e tratamento dos

dados, variações do preço das ações, foram realizados os testes $\mathrm{t}$ e $\mathrm{F}$, sendo destacadas três possíveis hipóteses, conforme descrito no Quadro 4.

Quadro 4 - Hipóteses da pesquisa

H1 Empresas com GC (NM, N1 ou N2) possuem maior retorno que empresas tradicionais

H2 Empresas com GC (NM, N1 ou N2) possuem maior retorno que o Ibovespa

H3 Empresas com GC (NM, N1 ou N2) possuem menor risco que empresas tradicionais Fonte: os autores.

Antes de proceder aos testes estatísticos, devem-se calcular os retornos para cada período, de acordo com a
Fórmula (1). Em seguida, calcula-se o desvio-padrão para a série histórica em análise. 


$$
R=\ln \left(\frac{P_{t}}{P_{t-1}}\right) \quad \text { Fórmula (1), }
$$

onde Pt é o preço de fechamento no período t e Pt-1 é o mesmo preço de fechamento no período anterior.

$\mathrm{O}$ teste $\mathrm{t}$ informa se as empresas com GC possuem maior retorno que empresas tradicionais e, de maneira igual, maior retorno que o Ibovespa, apoiando-se na resposta às hipóteses de pesquisa 1 e 2. O teste em questão compara duas médias e verifica se a diferença delas é igual a zero, o que pressupõe normalidade, ou distintas de zero, sugerindo diferença entre os dois grupos.

Com relação ao teste $\mathrm{F}$, tem como objetivo informar se as empresas com GC possuem menor risco que empresas tradicionais, conforme hipótese de pesquisa 3. O teste citado compara duas variâncias e indica se a diferença delas é igual a zero, o que pressupõe não diferença nos riscos das empresas pesquisadas, ou distintas de zero, o que sugere diferença entre os dois grupos pesquisados.

Para ambos os testes estatísticos (t e F), foi utilizado um nível de significância de $5 \%$, ou seja, $95 \%$ de confiança e uma chance de $5 \%$ de erro.

\section{ANÁLISE DOS RESULTADOS}

Foram analisados os dados referentes às empresas de capital aberto do setor de consumo e varejo, listadas nos níveis de GC da B3, das quais 5\% (2 empresas) são listadas no Nível 1, 2,5\% (1 empresa) no Nível 2, 50\% (20 empresas) no Novo Mercado e, finalmente, 42,5\% (17 empresas) são tradicionais.

\subsection{Retorno de empresas listadas com GC}

O Quadro 5 apresenta o resultado do primeiro teste $\mathrm{t}$ para a primeira hipótese de pesquisa. 
Quadro 5 - Teste t - Hipótese de pesquisa 1

\begin{tabular}{lcc}
\hline & $\begin{array}{c}\text { N1 N2 NM } \\
\text { (Grupo 1) }\end{array}$ & $\begin{array}{c}\text { Tradicional } \\
\text { (Grupo 2) }\end{array}$ \\
\hline Média & $-0,00048656$ & 0,107109854 \\
Variância & $7,28046 \mathrm{E}-05$ & 0,008671525 \\
Observações & 23 & 17 \\
Variância agrupada & 0,003693318 & \\
Hipótese da diferença de média & 0 & \\
Gl & 38 & \\
Stat t & 5,535384602 & \\
$\mathrm{P}(\mathrm{T}<=\mathrm{t})$ unicaudal & $1,23473 \mathrm{E}-06$ & \\
$\mathrm{t}$ crítico unicaudal & 1,68595446 & \\
$\mathrm{P}(\mathrm{T}<=\mathrm{t})$ bicaudal & $2,46945 \mathrm{E}-06$ & \\
$\mathrm{t}$ crítico bicaudal & 2,024394164 & \\
\hline
\end{tabular}

Fonte: os autores.

Para um nível de significância de $5 \%$, o p-valor é inferior a $5 \%$, ou seja, as diferenças das médias dos dois grupos são distintas de zero. Portanto, as médias das empresas do grupo 1 são distintas do grupo 2. Nesse caso, rejeita-se a primeira hipótese de pesquisa $\left(\mathrm{H}_{1}\right)$. Para a presente amostra, no intervalo de tempo estudado, as empresas que se enquadram em algum nível de GC não apresentam melhores retornos do que empresas tradicionais.
É possível observar que o primeiro grupo, que contempla empresas listadas com algum nível de GC, obteve menor desempenho que o grupo 2, empresas tradicionais, obtendo uma média de 0,00048 para o primeiro grupo e 0,1071 para o segundo. O Quadro 6 apresenta o segundo teste $\mathrm{t}$, sobre a possibilidade de empresas com GC apresentarem melhor retorno que o Ibovespa.

Quadro 6 - Teste t - Hipótese de pesquisa 2

\begin{tabular}{lcc}
\hline & $\begin{array}{c}\text { N1 N2 NM } \\
\text { (Grupo1) }\end{array}$ & $\begin{array}{c}\text { Índice } \\
\text { Ibovespa }\end{array}$ \\
\hline Média & $-0,00049$ & 0,001715588 \\
Variância & $7,28 \mathrm{E}-05$ & - \\
Observações & 23 & 1 \\
Variância agrupada & $7,28 \mathrm{E}-05$ \\
Hipótese da diferença de média & 0 \\
Gl & 22 \\
Stat t & $-0,25265$ \\
P(T<=t) unicaudal & 0,401441 \\
$\mathrm{t}$ crítico unicaudal & 1,717144 \\
$\mathrm{P}(\mathrm{T}<=\mathrm{t})$ bicaudal & 0,802882 \\
$\mathrm{t}$ crítico bicaudal & 2,073873 \\
\hline
\end{tabular}

Fonte: os autores. 
$\mathrm{O}$ segundo teste $\mathrm{t}$ informa que não houve diferença entre o grupo 1 e $o$ Ibovespa, em termos de retorno, uma vez que o p-valor foi superior a 5\%. Portanto, a partir do teste $\mathrm{t}$ acima, não foi possível confirmar ou rejeitar a hipótese de pesquisa 2 .

Esses resultados corroboram os estudos de: Bampi et al. (2009), que utilizaram o teste paramétrico de análise de variância (Anova one-way); Da Silva, Nardi e Junior (2012), que empregaram os testes de Kolmogorov-Smirnov (para análise da normalidade), o teste paramétrico de médias emparelhadas e o teste não paramétrico de Wilcoxon (para medidas de risco absoluto); Nassiff (2014), aplicando o teste de correlação de Spearman; e Domingos e Moura (2015), com os testes de Kolmogorov-Smirnov e Mann-Whitney.

$$
\text { Contudo, destacam-se alguns }
$$
estudos que encontraram resultados opostos. Dos Santos e Pedreira (2008), que calcularam betas semestrais para cada Quadro 7 - Teste f - Hipótese de pesquisa 3

\begin{tabular}{lcc}
\hline Média & $\begin{array}{c}\text { N1 N2 NM } \\
\text { (Grupo1) }\end{array}$ & $\begin{array}{c}\text { Tradicional } \\
\text { (Grupo 2) }\end{array}$ \\
Variância & 0,061522 & 0,108787 \\
Observações & 0,001208 & 0,008338 \\
Gl & 23 & 17 \\
F & 22 & 16 \\
P(F<=f) unicaudal & 0,144849 & \\
F crítico unicaudal & $2,67 \mathrm{E}-05$ & \\
\hline
\end{tabular}

corporação, Serra et al. (2009), que empregaram a metodologia do teste de hipóteses para o IGC e Ibovespa, Gama et al. (2013), aplicando a metodologia de revisão bibliográfica e estudo de caso, De Oliveira Lima et al. (2015) com estatística descritiva, análises inferenciais, testes de média e análise de variância e Wang e Joseph (2017), que utilizaram outra metodologia estatística.

\subsection{Risco de empresas listadas com GC}

O Quadro abaixo reproduz o resultado do teste $\mathrm{F}$, hipótese de pesquisa 3 , no que diz respeito a se empresas com GC apresentam menor risco que empresas tradicionais.

Fonte: os autores. 
A partir do teste, verifica-se diferença entre os grupos 1 e 2 em termos de risco, uma vez que o p-valor foi superior a 5\%. Portanto, o risco do grupo 1 é diferente e menor do que o risco do grupo 2. Em outras palavras, empresas listadas em algum nível de GC apresentam menor risco do que as empresas tradicionais.

Estes resultados corroboram os estudos de: Matucheski, Clemente e Sandrini (2009), que utilizaram a estatística descritiva com base nos desviospadrão médios das variações dos preços Quadro 8 - Síntese dos resultados

\begin{tabular}{|c|c|c|c|}
\hline & Hipótese de pesquisa & Resultado & $\begin{array}{l}\text { Autores que encontraram } \\
\text { resultados similares }\end{array}$ \\
\hline H1 & $\begin{array}{l}\text { Empresas com GC (NM, N1 } \\
\text { ou N2) possuem maior retorno } \\
\text { que empresas tradicionais. }\end{array}$ & $\begin{array}{l}\text { Hipótese rejeitada (Quadro 5) } \\
\text { Empresas com GC nâ } \\
\text { apresentaram maior } \\
\text { frente às tradicionais. }\end{array}$ & $\begin{array}{l}\text { Bampi et al. (2009); Meurer } \\
\text { (2010); Da Silva, Nardi e } \\
\text { Junior (2012); De Alencar et } \\
\text { al. (2012); Nassiff (2014); } \\
\text { Domingos e Moura (2015). }\end{array}$ \\
\hline H2 & $\begin{array}{l}\text { Empresas com GC (NM, N1 } \\
\text { ou N2) possuem maior retorno } \\
\text { que o Ibovespa. }\end{array}$ & $\begin{array}{l}\text { Não foi possível confirmar ou } \\
\text { rejeitar esta hipótese de pesquisa, } \\
\text { pois não houve diferença entre os } \\
\text { grupos. }\end{array}$ & $\begin{array}{l}\text { Meurer (2010); De Alencar et } \\
\text { al. (2012). }\end{array}$ \\
\hline H3 & $\begin{array}{l}\text { Empresas com GC (NM, N1 } \\
\text { ou N2) possuem menor } \\
\text { risco que empresas } \\
\text { tradicionais. }\end{array}$ & $\begin{array}{l}\text { Hipótese confirmada } \\
\text { (Quadro 7). }\end{array}$ & $\begin{array}{l}\text { Matucheski, Clemente e } \\
\text { Sandrini (2009); Da Silva, } \\
\text { Nardi e Junior (2012); } \\
\text { McConnell e Qianru (2016). }\end{array}$ \\
\hline
\end{tabular}

Fonte: os autores.

\section{CONCLUSÃO}

O presente artigo teve como objetivo principal analisar as relações entre o desempenho dos retornos das ações e a classificação do nível de GC (N1, N2 e NM) no qual se enquadram as empresas brasileiras do setor de consumo e varejo de das ações; Da Silva, Nardi e Junior (2012), que empregaram os testes de KolmogorovSmirnov (para análise da normalidade), o teste paramétrico de médias emparelhadas e o teste não paramétrico de Wilcoxon (para medidas de risco absoluto); e McConnell e Qianru (2016), com o emprego de outras metologias estatísticas.

\subsection{Síntese dos resultados}

O Quadro 8 abaixo apresenta uma síntese dos resultados obtidos, a partir das hipóteses de pesquisa. 
de significância de 5\%, e delimitou a pesquisa a um setor relevante da economia: o de consumo e varejo. Após a sua devida aplicação, conclui-se que empresas que se enquadram em algum nível de GC não apresentam melhores retornos do que empresas tradicionais; ainda mais, essas empresas, listadas com GC, obtiveram menor desempenho do que as empresas tradicionais. Logo, rejeita-se a hipótese 1 da pesquisa.

Com relação à comparação do desempenho de empresas com GC e o índice Ibovespa, observa-se que não houve diferença entre os dois grupos. Portanto, com a análise somente do teste $t$, não foi possível confirmar ou rejeitar a hipótese de pesquisa número 2. No que se refere à análise do risco dos dois grupos, conclui-se que as empresas com GC apresentam menor risco do que as empresas tradicionais, confirmando então a hipótese de pesquisa número 3 .

Nesse sentido, o presente estudo pode contribuir para o mercado de capitais do setor de consumo e varejo, com evidências de que aderir a algum nível de
GC da B3 não garante resultados superiores aos concorrentes classificados como tradicionais.

Os resultados desta pesquisa corroboram os estudos de Bampi et al. (2009), Matucheski, Clemente e Sandrini (2009), Da Silva, Nardi e Junior (2012), Nassiff (2014), Domingos e Moura (2015) e McConnell e Qianru (2016). Em contrapartida, dão resultados opostos aos de Dos Santos e Pedreira (2008), Serra et al. (2009), Gama et al. (2013), De Oliveira Lima et al. (2015) e Wang e Joseph (2017).

Recomenda-se que, para uma análise completa da relação entre GC e retorno das ações, sejam realizados estudos semelhantes a este em outros segmentos do mercado, como, por exemplo, os setores de energia, construção e saúde. Sugerem-se, para trabalhos futuros, estudos sobre o impacto que o desempenho e a qualidade da gestão corporativa exercem sobre a oscilação do retorno e risco das ações, nos diversos setores de atuação. 


\section{REFERÊNCIAS}

AGUIAR, A. B.; CORRAR, Luiz João; BATISTELlA, Flávio Donizete. Adoção de práticas de GC e o comportamento das ações na Bovespa: evidências empíricas. Revista de Administração da USP, v. 39, n. 4, p. 338-347, 2004.

ANDRADE, Lélis Pedro de et al. GC: uma análise da relação do conselho de administração como valor de mercado e desempenho das empresas brasileiras. RAM. Revista de Administração Mackenzie, v. 10, n. 4, 2009.

BAMPI, Rodrigo Eduardo; SANTAROSSA, Eduardo Trapp; VERRUCK, Fabio; BARCELLOS, Paulo Fernando Pinto. Análise Comparaiva dos rendimentos das ações dos diferentes níveis de GC bovespa. XXIX Encontro Nacional de Engenharia de Produção. Salvador, BA, Brasil. 06 a 09 de outubro de 2009.

CADBURY Report. London Stock Exchange. Report of the Committee on the Financial Aspects of Corporate Governance, 1992.

COLOMBO, Jéfferson Augusto; GALLI, Oscar Claudino. GC no Brasil: níveis de governança e rendimentos anormais. Revista de Gestão dos Países de Língua Portuguesa, v. 11, n. 2-3, p. 117-128, 2012.

CORREIA, Laíse Ferraz; AMARAL, Hudson Fernandes; LOUVET, Um índice de avaliação da 24 qualidade da GC no Brasil.In: R. Cont. Fin. - USP, São Paulo, v. 22, n. 55, p. 45-63, jan./fev./mar./abr. 2011.

COSTA, Fernando Torres Baptista da. Relação entre cobertura da mídia, valor das empresas e liquidez das ações. Dissertação de Mestrado. Universidade de São Paulo, 2015.

DA SILVA, Edison Simoni; KAYO, Eduardo Kazuo; NARDI, Roberto Yocisuke Soejima. GC e criação de valor em aquisições. REGE-Revista de Gestão, v. 23, n. 3, p. 222-232, 2016.

DA SILVA, Ricardo Luiz Menezes; NARDI, Paula Carolina Ciampaglia; JUNIOR, Tabajara Pimenta. O impacto da migração das empresas para os níveis diferenciados de GC da BM\&F Bovespa sobre o risco e o retorno de suas ações. Revista de Administração da UFSM, v. 5, n. 2, p. 222-242, 2012. 
DALMÁCIO, Flávia Zóboli; NOSSA, Valcerino. A teoria de agência aplicada aos fundos de investimento. Brazilian Business Review, v. 1, n. 1, p. 31-44, 2004.

DE ALENCAR, Vinicius Barreto et al. DIVIDEND YIELD: IGC VERSUS IBOV. REAVIRevista Eletrônica do Alto Vale do Itajaí, v. 1, n. 1, p. 1-11, 2012.

DE ARRUDA, Giovana Silva; MADRUGA, Sérgio Rossi; DE FREITAS JUNIOR, Ney Izaguirry. A GC e a teoria da agência em consonância com a controladoria. Revista de Administração da UFSM, v. 1, n. 1, 2009.

DE OLIVEIRA LIMA, Sérgio Henrique et al. GC e desempenho econômico: uma análise dos indicadores de desempenho entre os três níveis do mercado diferenciado da BM\&FBOVESPA. REGE-Revista de Gestão, v. 22, n. 2, p. 187-204, 2015.

DE SANTANA, Luciana Magalhães et al. Relação entre disclosure socioambiental, práticas de GC e desempenho empresarial. Revista Organizações em Contexto-online, v. 11, n. 21, p. 49-72, 2015.

DE SOUZA, Pedro Bastos. Segmentos de listagem na BM\&F BOVESPA: GC e cumprimento da responsabilidade social da empresa. Temiminós Revista Científica, v. 6, n. 1, p. 6-21, 2016.

DO NASCIMENTO FERREIRA, Roberto et al. GC, eficiência, produtividade e desempenho. RAM. Revista de Administração Mackenzie, v. 14, n. 4, 2013.

DOMINGOS, Sylvia Rejane Magalhães; MOURA, André Aroldo Freitas. Reputação corporativa e desempenho: uma análise nas maiores companhias abertas do Brasil. Revista Brasileira de Contabilidade, n. 215, p. 30-43, 2015.

DOS SANTOS, José Odálio; PEDREIRA, Emerson Bazilio. Análise da relação entre o índice de GC e o preço das ações de empresas do setor de papel e celulose. Revista Administração em Diálogo-RAD, v. 6, n. 1, 2008.

EISSMANN, Julio Cezar; STEFENON, Stéfano Frizzo; ARRUDA, Petterson Andrade. Gestão Estratégica como Ferramenta para a GC: Um Estudo de Caso. Revista Espacios, v. 38, n. 16, p. 22-36, 2017.

GAMA, Uelington de Oliveira; BARBOSA, Marcus Vinicius; COUTINHO, Rhanica Evelise Toledo; FERREIRA, Salete Leone; NOVIKOFF, Cristina. GC: valor de mercado das ações no Brasil e o novo mercado. Outubro de 2013. 
GARCIA, F. A. GC. Trabalho de Conclusão de Curso, Instituto de Economia, Univ. Federal do Rio de Janeiro, Rio de Janeiro. 2005.

GOMES, Antônio Paulo Machado. Características da GC como estímulo à gestão físcal. Revista Contabilidade \& Finanças, v. 27, n. 71, p. 149-168, 2016.

GRÜN, Roberto. GC: atores e ações na construção de uma nova institucionalidade. XXVII Encontro Anual da Anpocs, 2003.

HENDRIKSEN, Eldon S.; BREDA, Michael F. Van. Teoria da contabilidade. São Paulo: Atlas, 1999.

JENSEN, Michael C.; MECKLING, William H. Theory of the firm: managerial behavior, agency costs and ownership structure. Journal of Financial Economics, v. 3, n. 4, p. 305360, 1976.

KONRAHT, Jonatan Marlon; SOUTES, Dione Olesczuk; DE ALENCAR, Roberta Carvalho. A relação entre a GC e o alisamento de resultados em empresas brasileiras. Revista Contabilidade e Controladoria, v. 8, n. 1, 2016.

LA PORTA, R.; LOPEZ-DE-SILANES, F.; SHLEIFER, A. Corporate ownership around the World. Journal of Finance, v. 57, p. 471-517, 1999.

LA PORTA, R.; SHLEIFER, A.; LOPEZ-DE-SILANES, F.; VISHNY, R. Investor protection and corporate governance. Journal of Financial Economics, v. 58, p. 3-27, 2000.

LODI, João Bosco. GC. Rio de Janeiro: Campus, 2000.

MACHADO, Thalyson Renan Bitencourt; ROGERS, Pablo. Remuneração dos executivos e o desempenho de companhias abertas brasileiras classificadas nos níveis de GC da BM\&FBOVESPA. Revista Mineira de Contabilidade, v. 17, n. 1, p. 5-13, 2016.

MARQUES, Maria da Conceição da Costa. Aplicação dos princípios da GC ao sector público. Revista de Administração Contemporânea, v. 11, n. 2, p. 11-26, 2007.

MATIAS-PEREIRA, José. A GC aplicada no setor público brasileiro. Administração Pública e Gestão Social, v. 2, n. 1, p. 109-134, 2010. 
MATUCHESKI, Silvio; CLEMENTE, Ademir; SANDRINI, Jackson Ciro. GC e volatilidade das ações negociadas na Bovespa na crise financeira de 2008. Revista Brasileira de Estratégia, v. 2, n. 2, p. 171-183, 2009.

MCCONNELL, John J.; QI, Qianru. Just Talk? CEO Succession Plan Disclosure, Corporate Governance and Firm Value. 2016.

MEANS, Gardiner C. Political and Economic Governance. Public Administration Review, Vol. 3, No. 2 (Spring), pp. 164-167, 1943.

MENDES, Andréa Paula Segatto. Teoria da Agência Aplicada à Análise de Relações entre os Participantes dos Processos de Cooperação Tecnológica Universidade-Empresa. 2001. 260f. Tese (Doutorado em Administração) - Faculdade de Economia, Administração e Contabilidade, São Paulo. 2001.

MEURER, Vitor Hugo. GC e rentabilidade. Trabalho de Conclusão de Curso (Graduação) UFRGS. Porto Alegre, 2010.

NASCIMENTO, A. M.; BIANCHI, M.; TERRA, P. R. S. A Controladoria como um mecanismo interno de GC: evidência de uma survey comparativa entre empresas de capital brasileiro e norte-americano. XXIX Encontro da Anpad, Salvador. 2006.

NASSIFF, Elaina. O desempenho das empresas que aderem GC na BM\&FBOVESPA. São Paulo, 2014.

PEREIRA, Maria Vanuza; SOUZA, André Luis. Paradoxos entre GC e Ocorrência de Práticas de Corrupção em Empresas Públicas: Uma Análise a Luz da Teoria da Agência. Revista Formadores, v. 10, n. 4, p. 5, 2017.

RIBEIRO, Henrique César Melo et al. GC: um estudo bibliométrico da produção científica das dissertações e teses brasileiras. Contabilidade, Gestão e Governança, v. 15, n. 3, 2012.

RIGHI, Marcelo Brutti; CERETTA, Paulo Sergio; DA SILVEIRA, Vinicius Girardi. Análise de desempenho financeiro setorial no mercado brasileiro. Estudos do CEPE, p. 252-272, 2012 .

ROSSONI, Luciano; MACHADO-DA-SILVA, Clovis L. Legitimidade, GC e Desempenho: Análise das Empresas da BM\&F Bovespa (Legitimacy, Corporate Governance and 
Performance in BM\&F Bovespa). Revista de Administração de Empresas, 53(3), 272-289, 2013.

ROTTA, Claudio; HILlBRECTH, R. O.; NETO, Giacomo Balbinotto. A GC no mundo. XXIX Encontro da ANPAD, Brasília, 2005.

SAITO, Richard; SILVEIRA, Alexandre Di Miceli da. GC: custos de agência e estrutura de propriedade. Revista de Administração de Empresas, v. 48, n. 2, p. 79-86, 2008.

SERRA, Ricardo et al. IGC x Ibovespa: the impact of the rally of stocks entering the IGC. Revista de Administração-RAUSP, v. 44, n. 3, 2009.

SHLEIFER, A.; VISHNY, R. W. A survey of corporate governance. Journal of Finance. v. 52, p. 737-783, June 1997.

SILVA, E. C. GC nas empresas. São Paulo: Atlas, 2006.

SONZA, Igor; KLOECKNER, Gilberto. A GC influencia a eficiência das empresas brasileiras? Revista Contabilidade \& Finanças-USP, v. 25, n. 65, 2014.

TERRA, Paulo Renato Soares; DE LIMA, João Batista Nast. GC e a reação do mercado de capitais à divulgação das informações contábeis. Revista Contabilidade \& Finanças, v. 17, n. 42 , p. 35-49, 2006.

WANG, Zhihong; SARKIS, Joseph. Corporate social responsibility governance, outcomes, and financial performance. Journal of Cleaner Production, v. 162, p. 1607-1616, 2017.

WESTON, Fred. BRIGHAM, Eugene. Fundamentos da administração financeira. 2004. 